Research Article

\title{
Hypertension Treatment in Patients with Metabolic Syndrome and/or Type 2 Diabetes Mellitus: Analysis of the Therapy Effectivity and the Therapeutic Inertia in Outpatient Study
}

\author{
Štefan Farský (D), Andrea Strišková, and Marián Borčin \\ House of the Heart (Dom Srdca), Slovak League against Hypertension, Martin, Slovakia \\ Correspondence should be addressed to Štefan Farský; farsky@za.psg.sk
}

Received 7 October 2017; Revised 27 January 2018; Accepted 15 February 2018; Published 1 April 2018

Academic Editor: Luigina Guasti

Copyright (C) 2018 Štefan Farský et al. This is an open access article distributed under the Creative Commons Attribution License, which permits unrestricted use, distribution, and reproduction in any medium, provided the original work is properly cited.

We have analysed the database of 1,595 consecutive patients visiting our department of cardiology and internal medicine clinic in 2005-2014. The analysis included 13,990 visit records, and the average number of visits per patient was $8.5 \pm 7.0$. Our goals were to evaluate the effectivity of hypertension treatment as for drug choice, decrease of sBP and dBP associated with a certain drug, a drug combination, and therapeutic inertia in patients with metabolic syndrome and/or diabetes mellitus. The final number of patients for analysis who fulfilled the inclusion criteria for interpenetration of both diagnostic circles was 570 . Results. $15 \%$ of patients were treated using hypertension monotherapy, $70 \%$ of patients were treated using 2 - to 4 -drug combination therapy, and $15 \%$ of patients were treated using 5- to 6-drug combination. The drugs used most frequently were perindopril (perin), nitrendipine (nitre), amlodipine (amlo), telmisartan (telmi), hydrochlorothiazide (hydro), rilmenidine, and nebivolol (used in $>100$ patients). The most significant decrease of sBP was associated with treatment by nitre, hydro, telmi, and urapidil $(>19 \mathrm{mmHg})$. The most significant decrease of $\mathrm{dBP}$ was associated with treatment by nitre, hydro, telmi, and verapamil ( $>10 \mathrm{mmHg})$. The most significant decrease of both $\mathrm{sBP}$ and $\mathrm{dBP}$ was associated with treatment using 3-drug combination of telmi + hydro + spironolactone (41 and $16 \mathrm{mmHg}$, resp.), telmi + hydro + nitre (34 and $15 \mathrm{mmHg}$, resp.), and telmi + hydro + urapidil (34 and $15 \mathrm{mmHg}$, resp.). At the last visit, 281 out of 413 patients at the first visit had sBP $>140 \mathrm{mmHg}(68 \%)$; that is, sBP control was $32 \%$. At the last visit, 76 patients out of 217 at the first visit had $\mathrm{dBP}>90 \mathrm{mmHg}(35 \%)$; that is, $\mathrm{dBP}$ control was $65 \%$. Therapeutic inertia was calculated by evaluating the proportion of visits at which sBP was above the target for eligible visits minus the proportion of visits where the change was made in antihypertensive treatment (AHT), either medication type or dose, over the number of eligible visits, with the resultant value multiplied by the mean of the difference between the actual sBP and the target value at clinic visits. TIQ was counted at first 200 consecutive patients, and the average value was $57.30 \pm 147.20$. Conclusion. The study presents the real-life data concerning the difficulties in hypertension treatment in patients with concomitant metabolic syndrome and/or type 2 diabetes mellitus. sBP was controlled at 32\% patients only. The study results allow evaluating the effectivity of hypertension treatment as for drug choice, decrease of sBP and dBP associated with a certain drug, a drug combination, and therapeutic inertia in these patients.

\section{Introduction}

The aim of this study was to evaluate the effectivity of hypertension treatment as for drug choice, measure of decrease of systolic blood pressure (sBP) and diastolic blood pressure (dBP) associated with a certain drug, a drug combination, and therapeutic inertia in patients with metabolic syndrome and/or diabetes mellitus. It is well known from both clinical practice and literature how difficult it is to treat these patients with $\mathrm{sBP}$ and $\mathrm{dBP}$ to target values which are in this case a bit lower than the target values for hypertension patients without metabolic syndrome and/or diabetes mellitus. We have decided to follow the European Society of Hypertension and European Society of Cardiology 2013 
guidelines (they were valid at the time of documenting the database), with systolic blood pressure goals for patients with diabetes mellitus $<140 \mathrm{mmHg}$, diastolic blood pressure goals for patients with diabetes $<85 \mathrm{mmHg}$, and blood pressure goals for patients with metabolic syndrome $<140 / 90 \mathrm{mmHg}[1,2]$. Thus, our unified BP target values used in this study were $<140 / 90 \mathrm{mmHg}$, that is, a little less strict value than that could be expected with regard to the current SPRINT study results [3]. Our target values were based on the real-life data from our departments for outpatients, where BP values of $140 / 90 \mathrm{mmHg}$ for diabetic (and often obese) patients could often be considered as a treatment success. This approach supports the 2016 Standards of the American Diabetes Association where the target values for diabetic patients are commonly determined as $<140 / 90 \mathrm{mmHg}$. Lower BP targets, such as $<130 / 80 \mathrm{mmHg}$, may be appropriate for certain individuals, such as younger patients, if they can be achieved without undue treatment burden [4].

Rather than the patients' proportion in the target values, more interesting to us were the questions about what measure of $\mathrm{BP}$ decrease would be associated with using certain drugs or what measure of BP decrease we can expect from this hypertension drug treatment. The same was followed for combination treatment.

To physicians, being effective in the hypertension treatment means not to remain passive at the regular patient visits and to adjust the drug choice and dosing to the actual $\mathrm{BP}$ values if they exceed the target BP. Therefore, the therapeutic inertia evaluation should be a part of the quality assessment in hypertension management [5-7].

\section{Materials and Methods}

We have analysed the database of 1,595 consecutive patients visiting our department of cardiology and internal medicine clinic for outpatients in 2005-2014; all the patients were in the secondary prevention area. The analysis included 13,990 visit records, and the average number of visits per patient was $8.5 \pm 7.0$.

From the database, we have chosen a final number of patients who are as follows (Figure 1):

(i) Selected patients with I10 diagnoses.

(ii) Selected patients with "hypertension" as a keyword.

(iii) Previous two lists of patients have been merged into the first diagnostic circle.

(iv) Selected patients with E78.2 diagnoses.

(v) Selected patients with "metabolic syndrome" as a keyword.

(vi) Selected patients with "abdominal obesity" as a keyword.

(vii) Selected patients with "diabetes mellitus" and "DM2" as a keyword.

(viii) Previous four lists of patients have been merged into the second diagnostic circle.

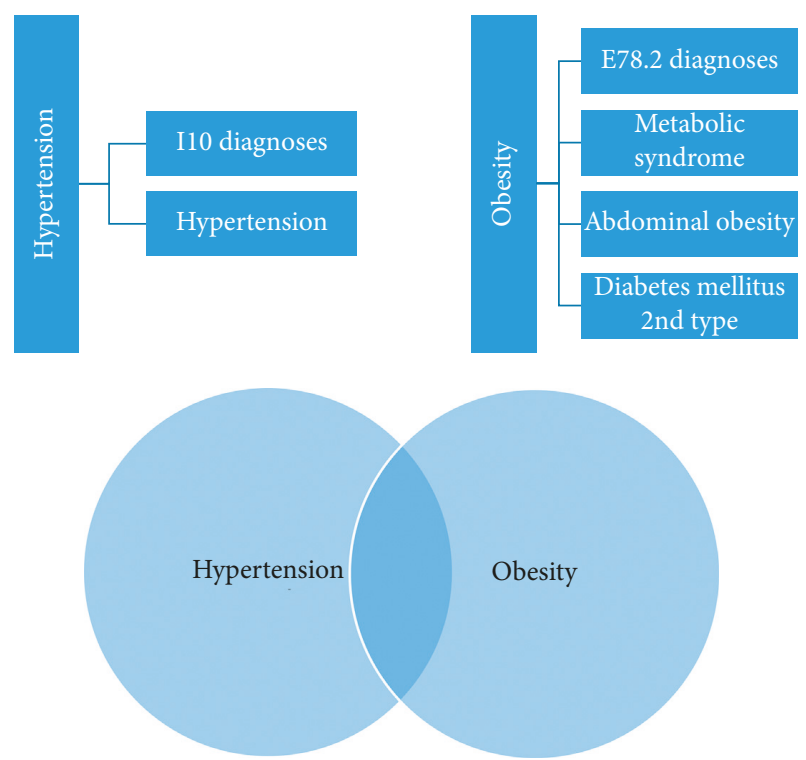

FIGURE 1: Patient selection from the database (interpenetration of 2 circles).

We obtained a list of patients who had fulfilled the main intersection of both first and second circles. Subsequently, patients were filtered out so that each patient would be counted just once. We selected 636 patients meeting the requirement for both diagnostic circles. However, after removing those patients who had one medical visit only, no drug therapy, or whose blood pressure had not been not measured, we obtained a final database of 570 patients (304 males and 266 females, and the age average was 64 years).

2.1. The Procedure for Obtaining Data from the Database. For the final database of patients, following the alphabetical order, the data were assigned to the individual patient, that is, age, sex, systolic blood pressure values (SBP) and diastolic blood pressure values (DBP) at the beginning, during, and at the end of treatment, and antihypertensive drugs used for the hypertension treatment.

2.2. Calculation of Therapeutic Inertia (TIQ). TIQ was calculated by determining the proportion of visits at which systolic blood pressure was above the target for eligible visits minus the proportion of these visits where the change was made only in antihypertensive treatment (AHT), either medication type or dose, over the number of total eligible visits, and the resultant value was multiplied by the mean of differences between the actual sBP and the target values at all the clinical visits.

$\mathrm{TIQ}=((\%$ visits with $>\mathrm{TARGET}-\% \Delta \mathrm{AHT} /$ visits $) /$ total number of visits) $*$ mean value of differences between actual sBP - TARGET sBP values during all visits.

Theoretically, the best physician approach means to change the therapy at every visit during which the sBP exceeds the target value. Examples of optimal and high inertia calculations are in Figures 2 and 3. 


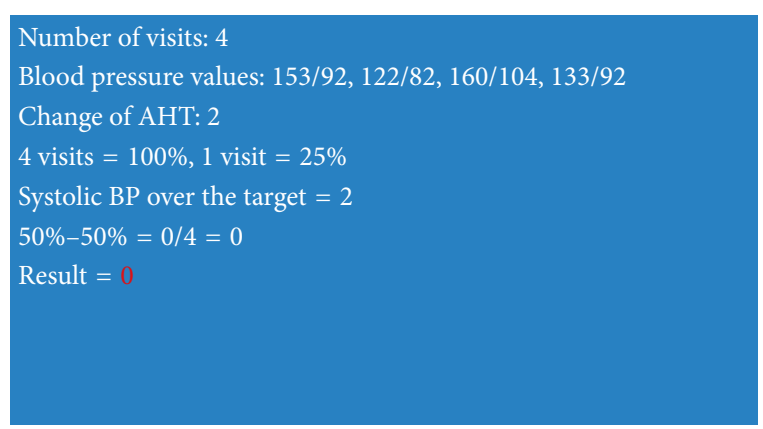

FIgURE 2: Example of the optimal value of inertia.

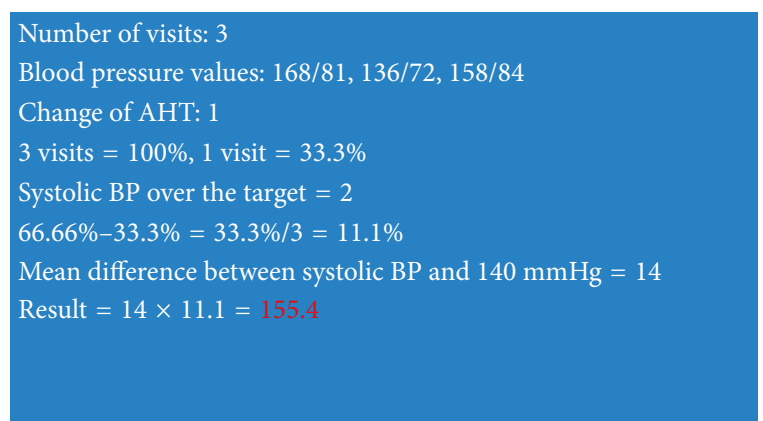

FIgURE 3: Example of the high value of inertia.

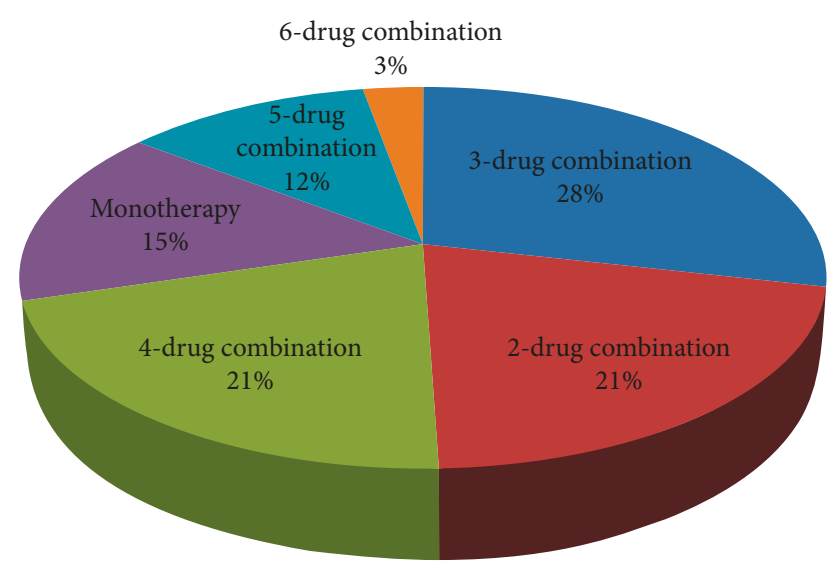

FIgURE 4: Monotherapy and combination therapy representation.

\section{Results}

$15 \%$ of patients were treated using hypertension monotherapy, $70 \%$ of patients were treated using 2- to 4 -drug combination therapy, and $15 \%$ of patients were treated using 5- to 6-drug combination (Figure 4). The drugs used most frequently (Figure 5) were perindopril (perin), nitrendipine (nitre), amlodipine (amlo), telmisartan (telmi), hydrochlorothiazide (hydro), rilmenidine, and nebivolol (used in $>100$ patients, the so-called "first league"). Figure 6 shows the drugs used less frequently (the "second league"). The most frequently used drugs and associated averaged changes of both sBP and dBP are presented in Table 1.

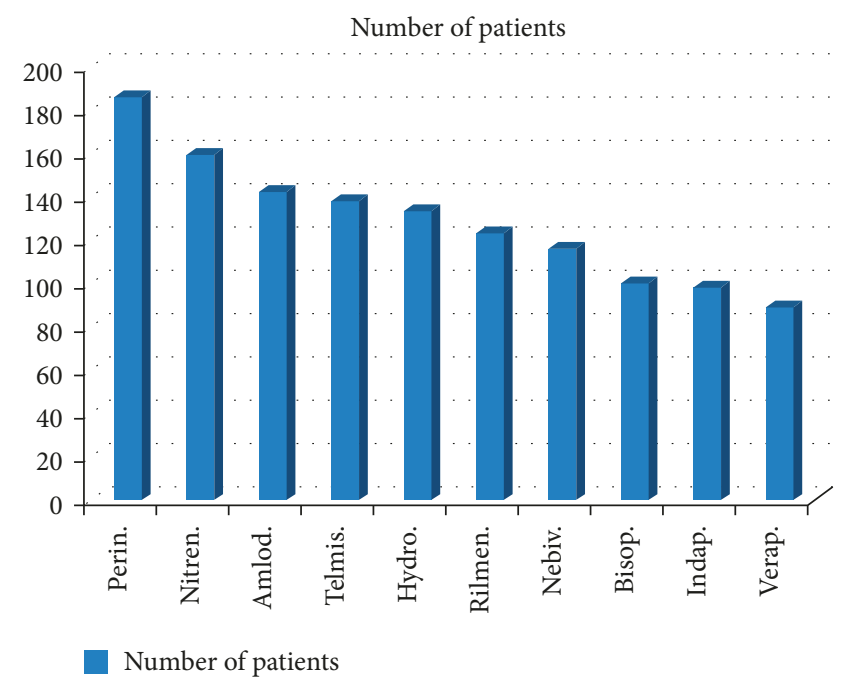

Figure 5: The number of patients treated using different drugs: "first league." Perin. = perindopril, nitren. = nitrendipine, amlod. = amlodipine, telmis. = telmisartan, hydro. = hydrochlorothiazide, rilmen. $=$ rilmenidine,$\quad$ nebiv. $=$ nebivolol, $\quad$ bisop. $=$ bisoprolol, indap. $=$ indapamide, and verap. $=$ verapamil.

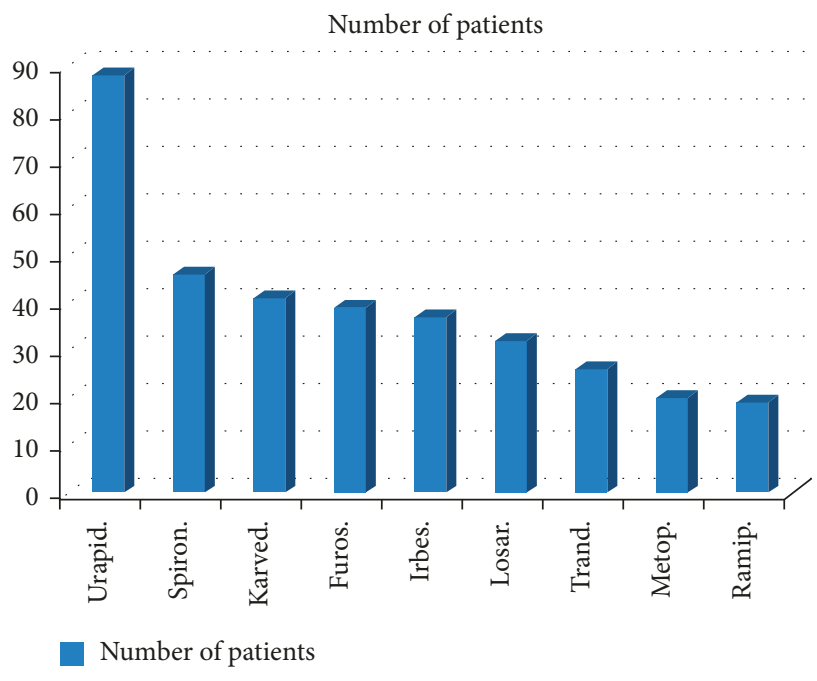

Figure 6: The number of patients treated using different drugs: "second league." Urapid. = urapidil, spiron. = spironolactone, karved. $=$ karvedilol, furos. $=$ furosemide, irbes. $=$ irbesartan, losar. $=$ losartan, $\quad$ trand $=$ trandolapril, metop. $=$ metoprolol, and ramip. $=$ ramipril.

The most significant decrease of $\mathrm{sBP}(>19 \mathrm{mmHg})$ was associated with the treatment by nitre, hydro, telmi, and urapidil, and the most significant decrease of dBP ( $>10 \mathrm{mmHg}$ ) was associated with the treatment by nitre, hydro, telmi, and verapamil (Figures 7 and 8). As for the combination therapy, the effects of 2-drug combination and the associated averaged sBP and $\mathrm{dBP}$ are presented in Table 2. The most significant decrease of both $\mathrm{sBP}$ and $\mathrm{dBP}$ was associated with treatment using 3-drug combination (Table 3) of telmi + hydro + spironolactone (41 or $16 \mathrm{mmHg}$, resp.), telmi 
TABLE 1: Most frequently used drugs and associated BP changes.

\begin{tabular}{|c|c|c|c|c|c|c|c|c|c|}
\hline & \multirow{2}{*}{$\begin{array}{l}\text { Number of } \\
\text { patients }\end{array}$} & \multicolumn{2}{|c|}{ Start } & \multicolumn{2}{|c|}{ Finish } & \multirow{2}{*}{$\begin{array}{c}\text { Average } \\
\text { decrease } \\
\text { of sBP }\end{array}$} & \multirow{2}{*}{$\begin{array}{c}\text { Average } \\
\text { decrease } \\
\text { of dBP }\end{array}$} & \multirow[b]{2}{*}{$\begin{array}{l}\mathrm{SD} \\
\mathrm{sBP}\end{array}$} & \multirow[b]{2}{*}{$\begin{array}{l}\mathrm{SD} \\
\mathrm{dBP}\end{array}$} \\
\hline & & $\begin{array}{c}\text { Average } \\
\text { sBP }\end{array}$ & $\begin{array}{c}\text { Average } \\
\text { dBP }\end{array}$ & $\begin{array}{c}\text { Average } \\
\text { sBP }\end{array}$ & $\begin{array}{c}\text { Average } \\
\text { dBP }\end{array}$ & & & & \\
\hline Perindopril & 186 & 154.1 & 88.5 & 140.2 & 80.6 & 13.9 & 7.9 & 22.7 & 13.7 \\
\hline Nitrendipine & 159 & 165.1 & 89.7 & 142.3 & 77.5 & 22.8 & 12.2 & 29.0 & 15.4 \\
\hline Amlodipine & 142 & 153.0 & 88.0 & 141.0 & 80.0 & 12.0 & 8.0 & 24.0 & 14.0 \\
\hline Telmisartan & 138 & 161.8 & 88.8 & 140.2 & 77.6 & 21.7 & 11.2 & 28.9 & 15.1 \\
\hline Hydrochlorothiazide & 133 & 161.8 & 89.0 & 139.2 & 77.5 & 22.5 & 11.5 & 29.7 & 15.9 \\
\hline Rilmenidine & 123 & 159.1 & 90.3 & 143.9 & 81.8 & 15.2 & 8.5 & 28.8 & 15.8 \\
\hline Nebivolol & 116 & 158.3 & 89.6 & 141.9 & 80.8 & 16.4 & 8.9 & 24.5 & 13.9 \\
\hline Bisoprolol & 100 & 150.0 & 84.5 & 138.4 & 76.8 & 11.6 & 7.7 & 23.1 & 15.7 \\
\hline Indapamide & 98 & 156.2 & 88.4 & 139.4 & 80.4 & 16.8 & 8.0 & 21.4 & 12.9 \\
\hline Verapamil & 89 & 157.7 & 89.4 & 141.1 & 79.2 & 16.6 & 10.2 & 24.2 & 13.6 \\
\hline
\end{tabular}

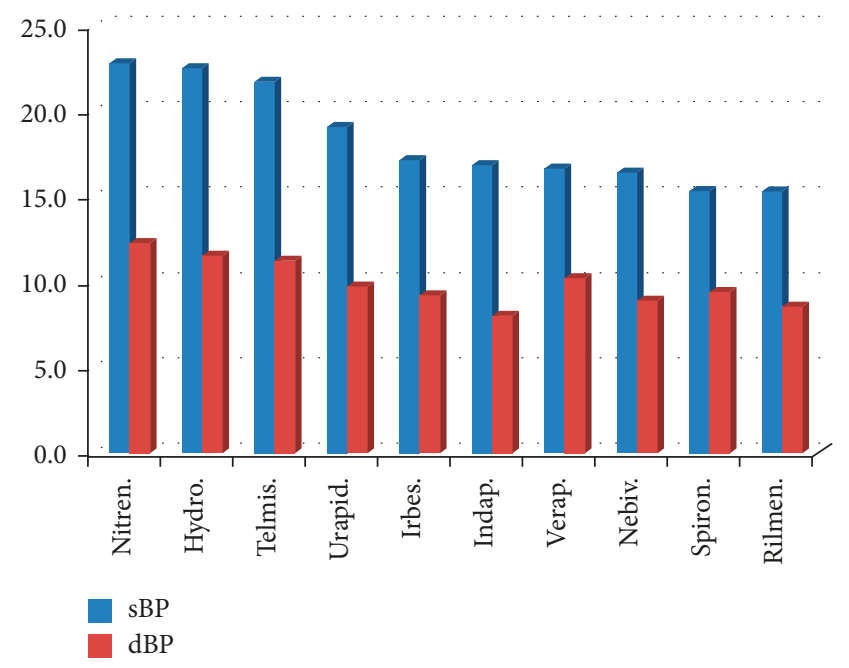

Figure 7: The most significant decrease of sBP and dBP associated with certain drugs (in $\mathrm{mmHg}$ ). Nitren. = nitrendipine, hydro. = hydrochlorothiazide, telmis. = telmisartan, urapid. = urapidil, irbes. $=$ irbesartan, indap.$=$ indapamide, verap.$=$ verapamil, nebiv. $=$ nebivolol, spiron.$=$ spironolactone, and rilmen.$=$ rilmenidine .

+ hydro + nitre (34 or $15 \mathrm{mmHg}$, resp.), and telmi + hydro + urapidil (34 or $15 \mathrm{mmHg}$, resp.).

At the last visit, 281 out of 413 patients at the first visit had sBP > $140 \mathrm{mmHg}(68 \%)$; that is, sBP control was $32 \%$. At the last visit, 76 patients out of 217 at the first visit had $\mathrm{dBP}$ $>90 \mathrm{mmHg}(35 \%)$; that is, $\mathrm{dBP}$ control was $65 \%$.

TIQ was counted for the first 200 consecutive patients, and the average value was $57.30 \pm 147.20$.

\section{Discussion}

Hypertension jointly with abdominal obesity, combined dyslipidaemia, and insulin resistance constitutes a complex disease known as the metabolic syndrome. Hypertension and type 2 diabetes produce the so-called "lethal duo," which increases the risk of cardiovascular disease 2- to 4-fold over both diseases themselves (heart attack, stroke, ischemic heart disease, and microvascular complications). There is a significant interference of antihypertensive drugs with glycaemic control, insulin resistance, lipid metabolism, and

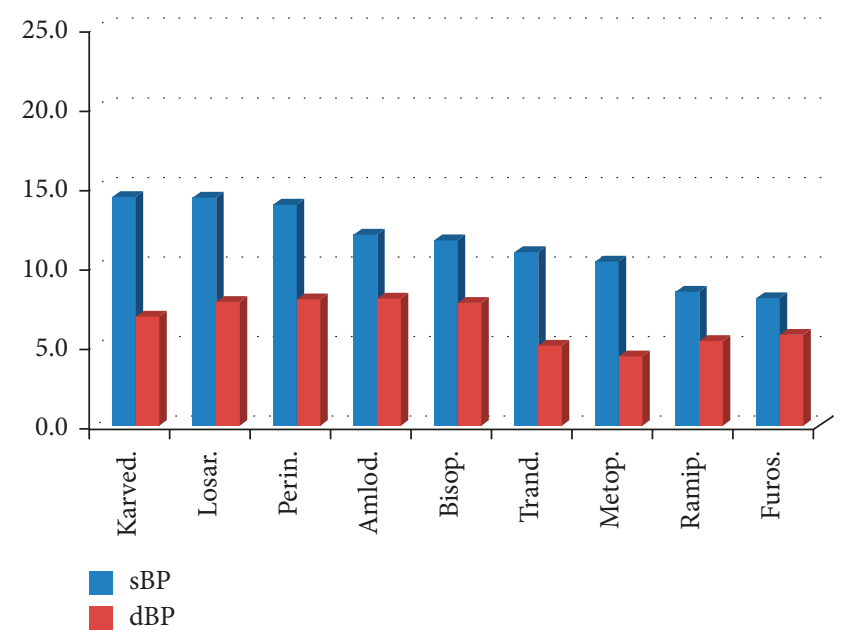

FIgURE 8: Less significant decrease of sBP and dBP associated with certain drugs (in $\mathrm{mmHg}$ ). Karved. $=$ karvedilol, losar. $=$ losartan, perin.$=$ perindopril,$\quad$ amlod.$=$ amlodipine,$\quad$ bisop.$=$ bisoprolol, trand.$=$ trandolapril, metop.$=$ metoprolol, ramip. $=$ ramipril, and furos. $=$ furosemide.

electrolyte balance. In the treatment of hypertension in patients with metabolic syndrome and/or diabetes mellitus, ACE inhibitors (or sartans) and calcium channel blockers are preferred for well-known nephroprotective, angioprotective, and metabolic effects. For these effects, these drugs are used even in the normotensive type 2 diabetic patients for albuminuria, retinopathy, and stroke prevention [8].

We have analysed the data of diabetics and metabolic syndrome patients together. Dividing the patients between diabetic and metabolic syndrome could lead to the decrease of the numbers of patients included in the group analysis and to the decrease of statistical power. Moreover, the margins between both groups are not sharp in every case, and patients suffering from diabetes usually belong to the metabolic syndrome group too. Analysis of the drug effectivity was not guided according to the class effect because there exist some differences between molecules inside every class group. Especially, their effectivities on high BP values were different as we can see in our results (different effect, for instance, 
TABle 2: Combination of two drugs: effect on BP values.

\begin{tabular}{|c|c|c|c|c|c|c|c|}
\hline & \multirow{2}{*}{$\begin{array}{c}\text { Number of } \\
\text { patients }\end{array}$} & \multicolumn{2}{|c|}{ Start } & \multicolumn{2}{|c|}{ End } & \multirow{2}{*}{$\begin{array}{l}\text { Average decrease } \\
\text { of } \mathrm{sBP}\end{array}$} & \multirow{2}{*}{$\begin{array}{c}\text { Average decrease } \\
\text { of } \mathrm{dBP}\end{array}$} \\
\hline & & Average sBP & Average $\mathrm{dBP}$ & Average sBP & Average dBP & & \\
\hline $\begin{array}{l}\text { Telmisartan } \\
\text { Hydrochlorothiazide }\end{array}$ & 83 & 165 & 90 & 138 & 76 & 27 & 14 \\
\hline $\begin{array}{l}\text { Irbesartan } \\
\text { Hydrochlorothiazide }\end{array}$ & 13 & 161 & 89 & 140 & 77 & 21 & 12 \\
\hline $\begin{array}{l}\text { Perindopril } \\
\text { Amlodipine }\end{array}$ & 87 & 157 & 91 & 142 & 81 & 15 & 9 \\
\hline $\begin{array}{l}\text { Perindopril } \\
\text { Nitrendipine }\end{array}$ & 36 & 156 & 87 & 137 & 78 & 19 & 9 \\
\hline $\begin{array}{l}\text { Nitrendipine } \\
\text { Spironolactone }\end{array}$ & 12 & 181 & 89 & 157 & 82 & 24 & 7 \\
\hline
\end{tabular}

TABLe 3: Combination of three drugs: effect on BP values.

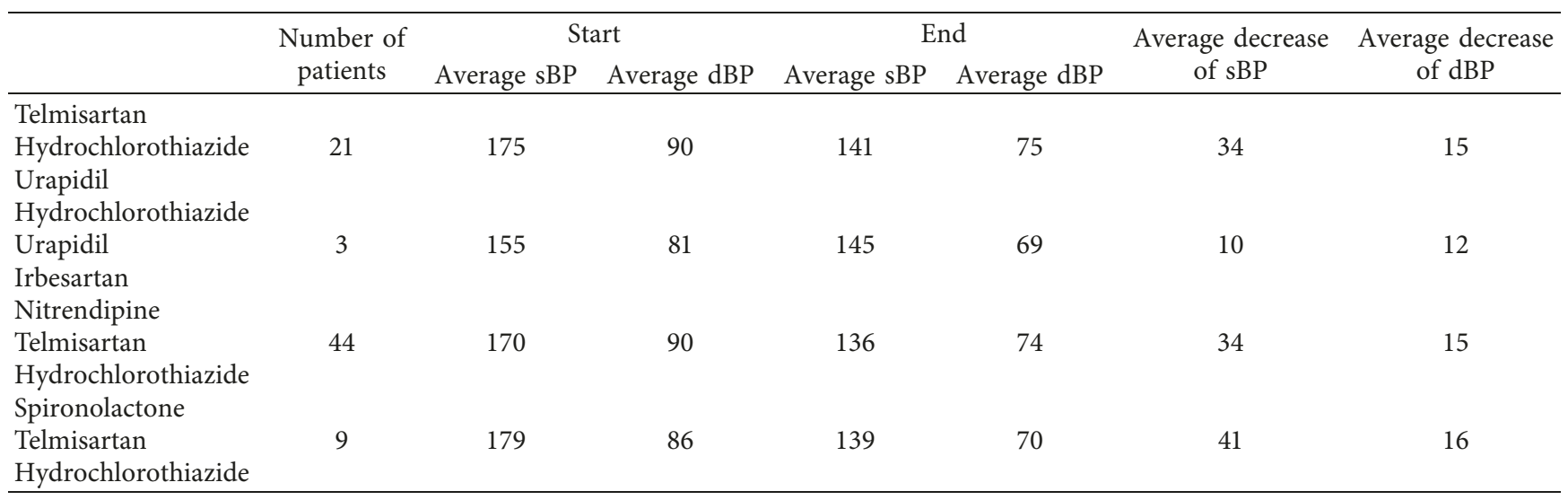

between amlodipine and nitrendipine and between nebivolol and bisoprolol).

From the group of $\beta$ blockers, in the view of the possible adverse reactions of $\beta 2$ receptor blockade (inhibition of insulin release, masking the symptoms of hypoglycaemia), the use of $\beta 1$ and selective vasodilators only (carvedilol and nebivolol) is recommended. Diuretics are particularly useful in the fixed combination of low-dose diuretic + ACE inhibitor or sartan. Calcium channel blockers are appropriate for this indication given their metabolic neutrality and excellent BP decrease efficiency. For patients with metabolic syndrome and type 2 diabetes mellitus, agonists of imidazoline receptors are suitable too, especially for their stimulation of insulin secretion, decrease of sympathetic hyperactivity, and inhibition of kidney sodium reabsorption $[9,10]$.

In our study, the drugs used most frequently were perindopril (perin), nitrendipine (nitre), amlodipine (amlo), telmisartan (telmi), hydrochlorothiazide (hydro), rilmenidine, and nebivolol, which corresponds to the recommendations mentioned above. More than $70 \%$ of patients were treated using 2- to 4-drug combinations, especially fixed combinations in the last years of the analysis. The most significant decrease of sBP $(>19 \mathrm{mmHg})$ was associated with the treatment with nitre, hydro, telmi, and urapidil, and the most significant decrease of $\mathrm{dBP} \quad(>10 \mathrm{mmHg})$ was associated with the treatment with nitre, hydro, telmi, and verapamil. The high efficiency of nitrendipine and telmisartan presented in the study was in concordance with our empirical, clinical experience. Nevertheless, we were surprised at the high position of hydrochlorothiazide treatment. However, it could be explained simply by the very common application of its fixed combination with telmisartan in our patient database.

In the case of the 2-drug combination, the most significant averaged sBP and $\mathrm{dBP}$ decrease was associated with the telmisartan-hydrochlorothiazide, nitrendipine-spironolactone, and irbesartan-hydrochlorothiazide combinations. The most significant decrease of both $\mathrm{sBP}$ and $\mathrm{dBP}$ was associated with treatment using the 3-drug combination of telmisartan + hydrochlorothiazide + spironolactone (41 and $16 \mathrm{mmHg}$, resp.), telmisartan + hydrochlorothiazide + nitrendipine (34 and $15 \mathrm{mmHg}$, resp.), and telmisartan + hydrochlorothiazide + urapidil (34 and $15 \mathrm{mmHg}$, resp.).

In spite of the really impressive effects of the drugs on $\mathrm{BP}$ values, the target values were reached for sBP in onethird of hypertensive patients and for dBP in two-thirds of the patients only. If we used the stricter target values $(135 / 85 \mathrm{mmHg}$ or less), then the hypertension control would be even lower. These data support the empirical experience from the clinical practice that hypertension pharmacotherapy in patients with concomitant metabolic syndrome 
and/or type 2 diabetes is difficult, where resistant hypertension is often expressed as a true form (in patients with obesity, sleep apnoea syndrome, and autonomic neuropathy) or as a false form (nonadherence).

Therapeutic inertia is defined as the provider's failure to change the therapy when treatment goals are unmet and contributes to higher prevalence of uncontrolled hypertension. Regular assessment of the inertia score leads to decreased score in time and refers to the accuracy of the therapy. Our score of 57.3 is comparable to the results of some other studies [4-6]. The higher SD value could reflect the database's heterogeneity and a higher variability of the BP values which is typical especially of diabetic patients with autonomic neuropathy.

4.1. Limitations. Patient selection in the database was not carried out in accordance with the Adult Treatment Panel or American Diabetes Association criteria, but using keywords. Data on $24 \mathrm{~h}$ ambulatory blood pressure monitoring are lacking; in our country, this method is not applied in all the patients treated for hypertension, and the indication is restricted for the special cases. Effectivity according to the dosage evaluation was not done. It could lead to the decrease of the numbers of patients included in the group analysis and to the decrease of statistical power. Dosage at every patient was adjusted according to the actual BP values, and dosage was currently changed during the follow-up. So, it was impossible to choose only one dose for analysis. Home BP values referred by patients were also taken into account during the dosing process. Mutual interactions of many drugs used in hypertension therapy, often more than 3-drug combinations, were not taken into consideration, and adjustment for another drug's effects, weight, salt reduction, and so on was not performed. The whole database was recorded by one experienced clinical cardiologist only, which means that personal preferences could influence the drug choice. However, no conflicts of interest were present to disclose, and principal effort was only to reach optimal BP control based on more than 40 years of clinical experience and continual medical education.

\section{Conclusion}

The study presents the real-life data concerning the difficulties of hypertension treatment in patients with concomitant metabolic syndrome and/or type 2 diabetes mellitus. sBP was controlled in $32 \%$ of patients only. The study results allow evaluating the effectivity of hypertension treatment as for the drug choice, decrease of sBP and $\mathrm{dBP}$ associated with a certain drug, a drug combination, and therapeutic inertia in patients with metabolic syndrome and/or diabetes mellitus. The score of therapeutic inertia evaluation may contribute to the improvement of hypertension control and should be a part of the quality assessment in hypertension management.

\section{Disclosure}

The earlier version of this work has been presented as a poster at Joint Meeting of International Society of
Hypertension and European Hypertension Society in Athens, Greece, on June 13-16, 2014.

\section{Conflicts of Interest}

The authors declare that they have no conflicts of interest.

\section{References}

[1] G. Mancia, R. Fagard, K. Narkiewicz et al., "2013 ESH/ESC Guidelines for the management of arterial hypertension," European Heart Journal, vol. 34, no. 28, pp. 2159-2219, 2013.

[2] L. Rydén, P. J. Grant, and S. D. Anker et al., "ESC guidelines on diabetes, prediabetes, and cardiovascular disease developed in collaboration with the EASD," European Heart Journal, vol. 34, no. 39, pp. 3035-3087, 2013.

[3] The SPRINT Research Group, "A randomized trial of intensive versus standard blood-pressure control," New England Journal of Medicine, vol. 373, no. 22, pp. 2103-2116, 2015.

[4] American Diabetes Association Standards of Medical Care in Diabetes, "Cardiovascular disease and risk management," Diabetes Care, vol. 39, no. 1, pp. S60-S71, 2016.

[5] E. Okonofua, K. N. Simpson, A. Jesri et al., "Therapeutic inertia is an impediment to achieving the Healthy People 2010 blood pressure control goals," Hypertension, vol. 47, no. 3, pp. $345-351,2006$.

[6] C. M. Reid, A. J. Owen, M. Bond et al., "Quantification of therapeutic inertia in primary care-based hypertension management," in Proceedings of the 32nd Annual Scientific Meeting of the High Blood Pressure Research Council of Australia Melbourne, p. 70, Australia, December 2010.

[7] N. Desai, V. M. Saraswathy, K. Hunter et al., "Prevalence of true therapeutic inertia in blood pressure control in an academic chronic kidney disease clinic," Journal of Clinical Hypertension, vol. 15, no. 6, pp. 375-379, 2013.

[8] R. Schrier, R. O. Estacio, A. Esler, and P. Mehler, "Effects of aggressive blood pressure control in normotensive type 2 diabetic patients on albuminuria, retinopathy and strokes," Kidney International, vol. 61, no. 3, pp. 1086-1097, 2002.

[9] D. Mesárošová, E. Hirnerová, and B. Krahulec, "Artériová hypertenzia u diabetikov," Vascular Medicine, vol. 5, pp. 63-65, 2013.

[10] S. Farský, "Štúdia SYMPATHY: Sympatiková hyperaktivita v patogenéze hypertenzie pri metabolickom syndróme," Bratislavske Lekarske Listy, vol. 45, no. 2-3, 2007. 


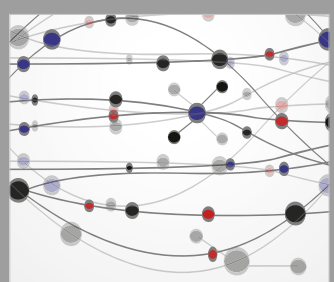

The Scientific World Journal
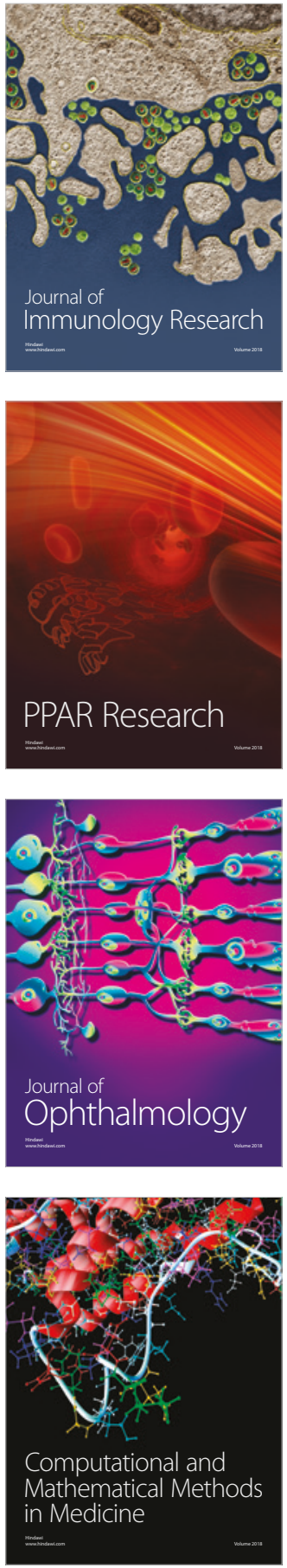

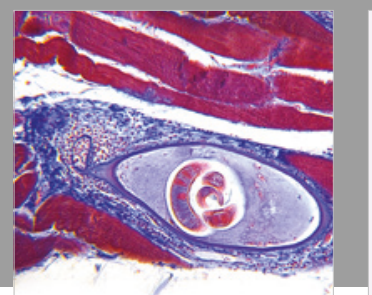

Gastroenterology Research and Practice

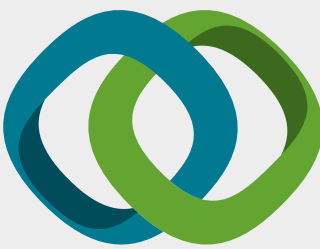

\section{Hindawi}

Submit your manuscripts at

www.hindawi.com
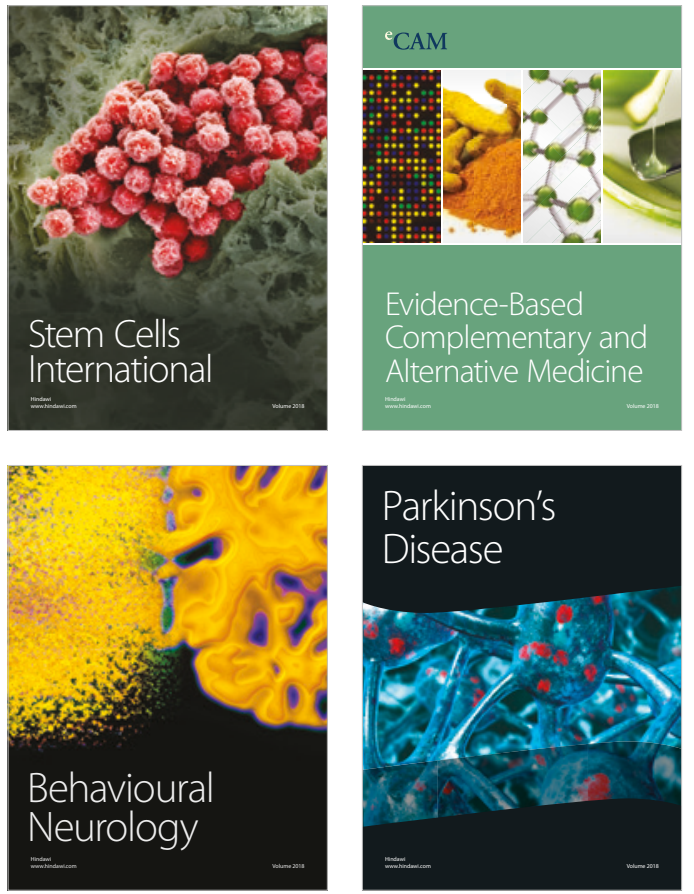

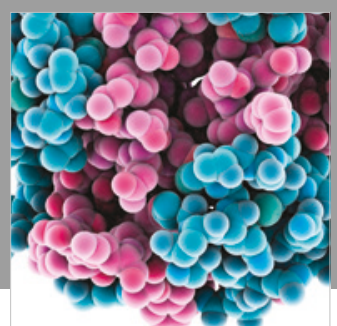

ournal of

Diabetes Research

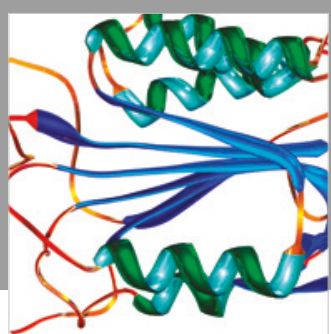

Disease Markers
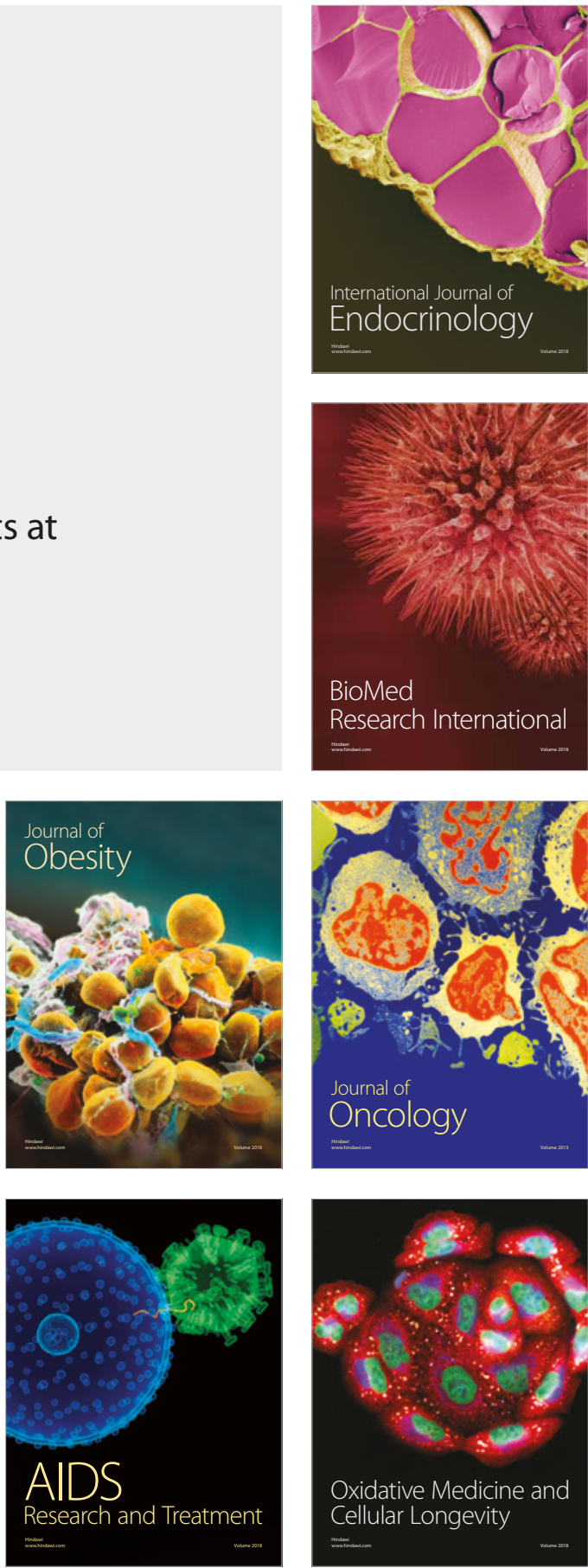